\title{
Effect of Bleaching Gels on Surface Roughness of Nanofilled Composite Resins
}

\author{
Linda Wanga \\ Luciana Fávaro Francisconia \\ Maria Teresa Atta \\ Jean Rodrigo dos Santos ${ }^{b}$ \\ Natália Coelho Del Padre ${ }^{b}$ \\ Alcides Gonini-Júnior ${ }^{b}$ \\ Karen Barros Parron Fernandes ${ }^{b}$
}

\section{ABSTRACT}

Objectives: The aim of this study was to investigate the superficial texture of composite restorations after different bleaching protocols.

Methods: Filtek Supreme (S), Filtek Z350 (F), and Grandio (G) were compared to Opallis (O) and Filtek Z250 (Z) (control microhybrid composites) and to bovine enamel using three different bleaching agents: 35\% hydrogen peroxide Whiteness HP (WHP), 35\% Whiteness HP MAXX (WMAXX) and $16 \%$ carbamide peroxide Whiteness Standard (WS). Six specimens from each composite were treated using each bleaching agent, according to the manufacturers' instructions. Three random sites were measured for superficial roughness (Hommel Tester T 1000) weekly for each sample. Data were analyzed for each bleaching system using two-way ANOVA and Bonferroni tests at $5 \%$ significance level.

Results: WHP treatment significantly altered the Filtek Supreme composite over time. When WMAXX was used, Grandio displayed the most significant alterations in surface roughness throughout the evaluation period, which was not observed for the other nanocomposites. Using WS, Filtek Z250 presented significant surface alterations over time, which was not seen in the nanofilled materials.

Conclusions: Surface roughness alteration was material and time-dependent. The bleaching gels affected nanofilled and microhybrid composite resins. Enamel was the surface less affected by bleaching. (Eur J Dent 2011;5:173-179)

Key words: Tooth bleaching; Nanotechnology; Resin composites; Surface roughness.

a Department of Operative Dentistry, Endodontics and Dental Materials of the School of Dentistry of Bauru, University of São Paulo, Bauru, SP, Brazil.

School of Dentistry of University North of Paraná UNOPAR, Londrina, PR, Brazil.

- Corresponding author: Dr. Linda Wang Department of Operative Dentistry, Endodontics and Dental Materials Alameda Octávio Pinheiro Brisolla, 9-75, Bauru, SP, Brazil

Phone: +55-14-3235-8325 Fax: +55-14-3235-8523

E-mail: wanglinda01dyahoo.com.br

wang.lindađusp.br

\section{INTRODUCTION}

Currently, dental bleaching is one of the most commonly used dental esthetic clinical procedures. This treatment offers higher self-esteem to patients with minor consequences to teeth and gingival tissues when it is well indicated and performed. ${ }^{1}$ In general, bleaching is a conservative treatment and has been shown to be both efficient and safe. ${ }^{1,2}$

When resin composite restorations are clinically used, they are frequently removed after bleaching 
due to possible negative physical-mechanical consequences. ${ }^{3,4}$ However, there are situations where restoration is required before bleaching, such as non-carious cervical lesions, to avoid sensitivity during the bleaching procedure. ${ }^{5}$ Other common situation when many practitioners dispense to restoration removal is when the restorative material is placed in distal areas of premolars when there is no esthetic compromise with respect to resin color change after bleaching. ${ }^{5}$ The color change of composite resins due to bleaching is a relevant reason that can require restoration replacement., 3

The consequences of bleaching of resin-based materials can vary according to resin and bleaching gel compositions and frequency and duration of exposure. ${ }^{3}$ Alterations in microhardness and roughness are commonly used to analyze the possible negative effects of bleaching products..$^{7-11}$ An increase in superficial roughness is clinically relevant, and irrespective of etiological factor, increase in roughness results in accumulation of food residues and formation of biofilms, leading to periodontal tissue disease. ${ }^{12,13}$

Among the available resin categories, microhybrid resins are commonly used. Recently, materials engineers have developed nanofilled composites, which have been introduced into the dental market. ${ }^{14-17}$ These nanocomposites were developed in order to offer mechanical strength combined with well-polished surfaces that maintain their integrity during long-term use, even in the posterior regions of mouth. ${ }^{18,19}$

Given the possible alterations of properties of resin-based materials during bleaching, it is important to investigate the best category of composite resins for this application. These results would help to avoid the need for the replacement of composite restorations after bleaching treatments.

The aim of this study was to investigate the action of different bleaching gels on different composite resins by analyzing roughness changes in the composites. The null hypothesis was that no differences exist in the surface roughness of the tested materials over time.

\section{MATERIALS AND METHODS}

Tested composite materials are shown in Table 1 , and bleaching products used to present the chemical challenge are given in Table 2.

For each bleaching protocol, six specimens
(6 $\mathrm{mm}$ diameter $X 3 \mathrm{~mm}$ thickness) of each resin material were obtained using a stainless steel cylindrical mold. These samples were light-cured on both sides using a halogen lamp unit (Optlight Plus-Gnatus, Ribeirão Preto, SP, Brazil) according to the manufacturer's instructions. A mark was made on the untreated side of each sample to identify the surface type.

Enamel bovine blocks ( $4 \times 4 \times 2 \mathrm{~mm})$ were used as the control group. They were obtained from the buccal surface of bovine incisors stored in $0.1 \%$ thymol solution for no longer than 30 days. The enamel surface was mechanically flat (APL4. Arotec- Cotia, SP, Brazil) with water-cooled carborundum discs (\#320, 600 and 1200 of $\mathrm{Al}_{2} \mathrm{O}_{3}$ papers; Buehler, Lake Bluff, IL, USA). This series was completed with polishing using felt paper wet by diamond spray $(1 \mu \mathrm{m}$; Buehler, Lake Bluff, IL, USA). After each polishing step, specimens were ultrasonically cleaned immersed in deionized water in order to remove the residues. This polishing procedure resulted in a removal of about $100 \mu \mathrm{m}$ depth of enamel. ${ }^{20}$

In groups submitted to in-office bleaching (WHP and WMAXX), each specimen was exposed weekly to the bleaching protocol for a total of 10 minutes. When bubbles formed, a microbrush (FGM Produtos Odontológicos, Joinville, SC, Brazil) was used to disturb them. Light-activation was performed for $30 \mathrm{~s}$ after $5 \mathrm{~min}$ of bleaching. The specimens were washed and individually maintained in deionized water for a week until the new bleaching cycle. These procedures were performed for 4 consecutive weeks.

When home-bleaching material (WS) was used, bleaching was performed daily for 4 weeks. Gel was applied for 4 hours and covered. Then, the bleaching gel was washed out, and specimens were individually immersed in plastic vials in deionized water for $24 \mathrm{~h}$ until a new bleaching cycle.

Before each bleaching procedure and after each week, roughness surface measurements were performed using a roughness tester (Hommel Tester T 1000, HOMMELWERKE GmbH, Alte Tuttinger Strebe 20. D-7730. VS- Schwenningen). For each sample of all the groups, three randomized readings were performed on the challenged surfaces after each bleaching protocol. Margins and visible irregularities were avoided.

For each bleaching gel, each surface was as- 
sessed in triplicate. Data were used to perform a statistical analysis using two-way ANOVA and Bonferroni tests $(P<.05)$.

\section{RESULTS}

The two-way ANOVA showed significant differences at material and time factors as well as an interaction between these parameters for each tested bleaching gels $(P<.05)$.

When WHP was used (Figure 1), the surface roughness of Grandio was altered after the third week $(P<.05)$, but the roughness of it did not continue to change significantly after these time points $(P>$.05). Supreme showed significant surface changes between the first and final weeks of evaluation $(P<.05)$. There was no significant alteration to Filtek Z350, Z250, Opallis and enamel (control groups) (P>.05).

Under WMAXX challenge (Figure 2), Filtek Z350 was not affected at all over the evaluated time (P>.05); Grandio showed significant changes over time $(P<.05)$. Opallis, Filtek $Z 250$ and Supreme showed minor alterations over time, although no significant alterations were observed when comparing the initial and final roughness values ( $P>$.05). Only a significant change at the enamel surface was verified when the surface roughness at the second week was compared to the initial surface roughness $(\mathrm{P}<.05)$.

When analyzing data of surface roughness of composite resins challenged with WS (Figure 3), Supreme showed significant alterations only between the first and second weeks ( $P<.05)$; Grandio and Filtek Z350 were not significantly affected over time ( $P>$.05). Filtek $Z 250$ presented significant differences over time $(P<.05)$; enamel and Opallis also showed significant alteration of roughness from the second week to the final measurement $(P<.05)$

\section{DISCUSSION}

Bleaching is widely applied in approaches to improve dental esthetics. Due to the chemical nature of this reaction, it is expected that different

Table 1. Composites used in this study.

\begin{tabular}{|c|c|c|c|}
\hline Material & Manufacturer & Composition* & Filler size* \\
\hline Filtek Supreme (S) & $\begin{array}{l}\text { 3M ESPE, Dental Products, } \\
\text { St. Paul, MN, USA }\end{array}$ & $\begin{array}{c}\text { Bis-GMA, Bis-EMA, TEGMA, Zirconia/Silica } \\
\text { and Silica }(78.5 \% \mathrm{w} / \mathrm{w}, 59.5 \% \mathrm{v} / \mathrm{v})\end{array}$ & $\begin{array}{l}5 \mathrm{~nm} \text { to } 20 \mathrm{~nm} \\
0.6-1.4 \mu \mathrm{m} \text { (nanoclusters) }\end{array}$ \\
\hline Filtek Z350 (F) & $\begin{array}{l}\text { 3M ESPE, Dental Products, } \\
\text { St. Paul, MN, USA }\end{array}$ & $\begin{array}{c}\text { Bis-GMA, Bis-EMA, TEGMA, Zirconia/Silica } \\
\text { and Silica }(78.5 \% \mathrm{w} / \mathrm{w}, 59.5 \% \mathrm{v} / \mathrm{v})\end{array}$ & $\begin{array}{l}5 \mathrm{~nm} \text { to } 20 \mathrm{~nm} \\
0.6-1.4 \mu \mathrm{m} \text { (nanoclusters) }\end{array}$ \\
\hline Grandio $(G)$ & Voco, Cuxhaven, Germany & $\begin{array}{l}\text { Bis-GMA, TEGMA; inorganic fillers } \\
\qquad(87 \% \mathrm{w} / \mathrm{w}, 71.4 \% \mathrm{v} / \mathrm{v})\end{array}$ & $20-50 \mathrm{~nm}$ \\
\hline Opallis (0) & $\begin{array}{l}\text { FGM Produtos odontológicos, } \\
\text { Joinville, SC, Brazil }\end{array}$ & $\begin{array}{c}\text { Bis-GMA, Bis-EMA, TEGDMA, silanized } \\
\text { barium-aluminum glass and nanoparticle } \\
\text { (78.5\%) }\end{array}$ & $0.02-3 \mu \mathrm{m}$ \\
\hline Filtek Z250 (Z) & $\begin{array}{l}\text { 3M ESPE, Dental Products, } \\
\text { St. Paul, MN, USA }\end{array}$ & $\begin{array}{c}\text { Bis-GMA, Bis-EMA, UDMA, Zirconia/Silica } \\
\text { (82\% w/w, 60\% v/v). }\end{array}$ & $0.01-3.5 \mu \mathrm{m}$ \\
\hline
\end{tabular}

* Information was supplied by manufacturers' profile.

Bis-GMA= Bisphenol-A-glycidyl methacrylate; Bis-EMA= Ethoxylated bisphenol-A-glycidyl methacrylate; TEGMA= Triethylene glycol dimethacrylate; UDMA= Urethane dimethacrylate.

Table 2. Bleaching products.

\begin{tabular}{|c|c|c|c|}
\hline Material & Manufacturer & Composition & Application mode \\
\hline $\begin{array}{l}\text { Whiteness HP } \\
\text { (WHP) }\end{array}$ & $\begin{array}{l}\text { FGM Produtos odontológicos, Joinville, } \\
\text { SC, Brazil }\end{array}$ & $35 \%$ hydrogen peroxide & $\begin{array}{l}\text { In-Office (weekly ten-minute applica- } \\
\text { tion followed by photoactivation for four } \\
\text { consecutive weeks) }\end{array}$ \\
\hline $\begin{array}{l}\text { Whiteness HP MAXX } \\
\text { (WMAXX) }\end{array}$ & $\begin{array}{l}\text { FGM Produtos odontológicos, Joinville, } \\
\text { SC, Brazil }\end{array}$ & $\begin{array}{l}35 \% \text { hydrogen peroxide, light } \\
\text {-sensitive compounds to absorb } \\
\text { light energy* }\end{array}$ & $\begin{array}{l}\text { In-Office (weekly ten-minute application } \\
\text { for four consecutive weeks) }\end{array}$ \\
\hline $\begin{array}{l}\text { Whiteness Standard } \\
\text { (WS) }\end{array}$ & $\begin{array}{l}\text { FGM Produtos odontológicos, Joinville, } \\
\text { SC, Brazil }\end{array}$ & $16 \%$ carbamide peroxide & $\begin{array}{l}\text { At-Home (daily four-hour application for } \\
\text { two consecutive weeks) }\end{array}$ \\
\hline
\end{tabular}

* Manufacturer inform that this product contains specific components that aid to optimize heat from the light, improving its absorption and bleaching potential without provoke any pulp harmful, however it is not revealed. 
substrates in the oral environment, such as dental substrates and restorative materials, will respond differently. 4,6,20

Different bleaching systems are indicated for at-home or in-office treatments; the active ingredients of these two methods are typically carbamide peroxide and hydrogen peroxide, respectively. ${ }^{20-22}$ Due to these differences and the differences in concentration and frequency of use, these two methods can lead to distinct reactions with different restorative materials. 3,4,23

This investigation purposed to analyze the performance of composite resins compared to enamel surface using three bleaching gels.

WHP and WMAXX both utilize hydrogen peroxide and are commonly indicated as in-office-bleaching gels. WHP affected the surface roughness of nanofilled composites Grandio and Supreme after third and fourth weeks respectively, but enamel and microhybrid resins were not significantly affected (P>.05).

When WMAXX was used, Filtek Z350 was the only material not affected by this bleaching gel

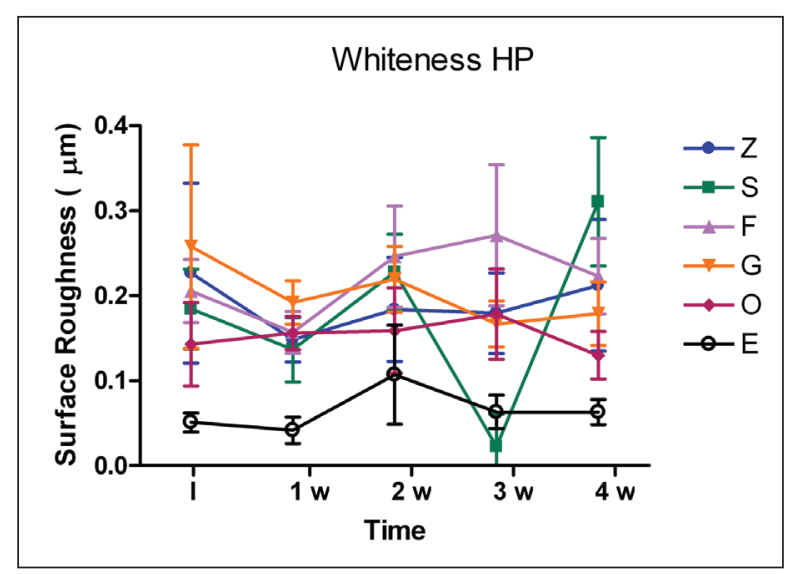

Figure 1. Roughness surface alterations thought 4-week Whiteness HP challenge.

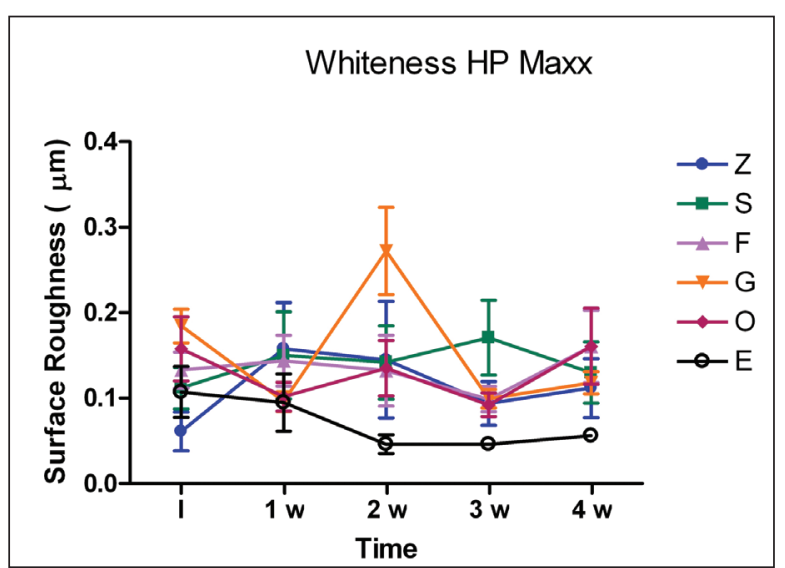

Figure 2. Roughness surface alterations thought 4-week Whiteness HP MAXX challenge. over time (P>.05). Filtek Z250, Grandio and Opallis demonstrated an increase in roughness with an increase in treatment time, but final and initial roughness were not statistically different ( $P>.05)$. WMAXX caused great changes surface roughness for all tested substrates; this effect could be due to the light-sensitive compounds that are found in WMAXX but not in the other hydrogen-peroxide bleaching systems (Table 2).

It has been shown in the literature that hydrogen peroxide gel can affect surface roughness. ${ }^{4,20}$ This roughening probably occurs due to attack of the organic matrix, causing a softening of the material and leading to gloss loss. ${ }^{23,24}$ Because different compounds are present in both the organic and inorganic fractions of restorative materials, even in products that are similarly categorized, these materials can react differently to the same treatment. This possibility was confirmed in this study. Light can increase the effects of hydrogen peroxide treatment on the surface roughness of restorative materials.

Under WS challenge, using an at-home carbamide peroxide gel, the material Filtek $Z 350$ was not as affected as Grandio and Filtek Supreme, indicating a better performance of nanofilled materials compared to the control groups. The other substrates (Filtek Z250, Opallis and enamell showed greater alterations in surface roughness over time. These data reinforce the statistical analysis that indicated an interaction between factors because the performance of the materials was not consistent with the null hypothesis.

It should be highlighted that even at-home bleaching is usually indicated for 2 weeks, it can

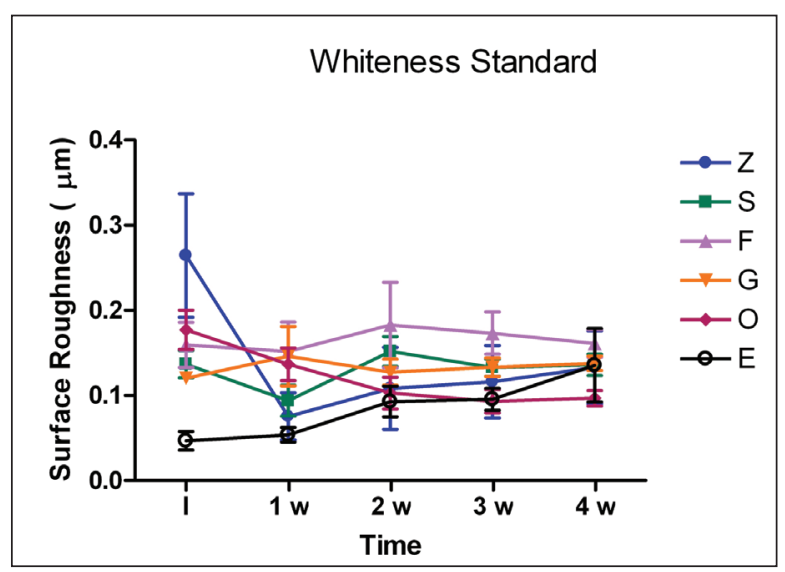

Figure 3. Roughness surface alterations thought 4-week daily Whiteness Standard challenge. 
be extended by the patients due to the lack of supervision of a professional. That was the reason we evaluated this effect in the same time to the in-office bleaching gels.

Rosentritt et $\mathrm{al}^{2}$ and Gurgan and Yalcin ${ }^{20}$ demonstrated that the performance of different composites is strongly influenced by different composition, especially due to monomers. This relationship indicates an interaction between the organic matrix and the bleaching agent. Musange and Ferracane ${ }^{25}$ verified the effect of monomers on experimental hybrid resins associated with nosilanized nanofilled. In that study, the results also showed a major susceptibility of organic matrixes to bleaching gels.

The influence of different bleaching gels depends on the oxidation process that occurs in the organic matrix, which can facilitate water absorption and lead to loss of particles, reducing superficial integrity and microhardness. ${ }^{5}$ In an extensive review based on original articles that investigated the action of bleaching gels on different material surfaces, Attin et $\mathrm{al}^{3}$ found that when composite resins are bleached, roughness can be a relevant tool to assess surface changes.

Roughness seems to be more affected by bleaching than microhardness. However, when saliva is present, adverse consequences are reduced because it acts as a protective barrier. Mor et al, ${ }^{12}$ Steinberg et $\mathrm{al}^{13}$ and Ulukapi et $\mathrm{al}^{2}$ also demonstrated both the ability of saliva to remineralize enamel after bleaching and its fluoride benefits. In the present study, as saliva was not considered, we could assess the potential of bleaching gels without this interference.

Bleaching can also alter the optical properties of composite resins, which depend on the composition of materials as well as on the bleaching agent. ${ }^{6,23}$

Results of the present study confirm that the action of the bleaching gel is not due to their low $\mathrm{pH}$ because the tested products had basic $\mathrm{pH}$. However, basic environment also can lead to chemical interactions in the oral scenario. ${ }^{24}$ In this case, one of the main speculations refers to the hydrolytic action caused by chemical solutions on the organic matrix of resin composites, which is composed of hydrophobic monomers and diluents. ${ }^{26,27}$

It is also noteworthy that specimens were stored in water during the challenge period, and so, specimens were stored under hydrolytic environment. There is evidence in the literature that demonstrates that water causes changes in the properties of restorative materials. These changes mainly occur at the interface between the filler and organic matrix. ${ }^{26,27}$ Alterations in the molecular structure of the matrix are under evaluation, and studies are being performed to make the matrix more resistant to chemical and mechanical challenges. ${ }^{28}$

The inorganic content of resin composites however, offers resistance to bleaching. Form, amount and distribution of fillers are all aspects that determine the clinical performance of these restorative materials. ${ }^{28,29}$ Despite advances in the evolution of composites, no material yet exists that is totally resistant to erosion/corrosion. Recent studies have reported that the durability of resinbased materials can be assured by polishing the restorations after bleaching. ${ }^{30,31}$

An interesting reaction between bleaching gel and composite resins was reported by Cho et al. ${ }^{32}$ According to the authors, fracture toughness, which is the measure of a material's ability to resist crack propagation, is considered to be a reliable indicator of the ability of dental materials to resist failure under load. The results of the $\mathrm{Cho}^{32}$ study showed a significant increase in fracture toughness values in the nanofilled composites after bleaching treatments. Cho et $\mathrm{al}^{32}$ also showed that the initial maximal polymerization of the control groups of other composites resulted in no change in fracture toughness values after bleaching. These reports indicate that the interactions of bleaching gels with resin composites require further investigation.

In the present study, we detected differences in roughness between composite resins and enamel. In all challenges of the present study, enamel showed the smoothest surface; even no polishing was considered after bleaching (Figures 1, 2 and 3). Reactions to each tested bleaching gel were shown to be material and time-dependent.

By the results presented in this study, we cannot affirm that nanofilled or microhybrid composite resins were more resistant under bleaching protocols as it was material and time dependent. It was evident that all composite resins were most affected compared to enamel surface. 


\section{CONCLUSIONS}

The changes in surface roughness of resin composites after bleaching are material and timedependent. The bleaching gels affected nanofilled and microhybrid composite resins. Enamel was the surface less affected by bleaching.

\section{ACKNOWLEDGEMENTS}

The authors are grateful for the donations of the manufacturers (FGM, VOCO and 3M ESPE) of all tested products and to FUNADESP for financial support.

\section{REFERENCES}

1. Kielbassa AM. Tooth bleaching-increasing patients' dental awareness. Quintessence Int 2006;37:673.

2. Ulukapi $H$. Effect of different bleaching techniques on enamel surface microhardness. Quintessence Int 2007;38:E201-E205.

3. Attin T, Hannig C, Wiegand A, Attin R. Effect of bleaching on restorative materials and restorations-a systematic review. Dent Mater 2004;20:852-861.

4. Taher NM. The effect of bleaching agents on the surface hardness of tooth colored restorative materials. J Contemp Dent Pract 2005;6:18-26.

5. Wattanapayungkul P, Yap AU, Chooi KW, Lee MF, Selamat RS, Zhou RD. The effect of home bleaching agents on the surface roughness of tooth-colored restoratives with time. Oper Dent 2004;29:398-403.

6. Rosentritt M, Lang R, Plein T, Behr M, Handel G. Discoloration of restorative materials after bleaching application. Quintessence Int 2005;36:33-39.

7. Arends J, Jongebloed WL, Goldberg M. Schuthof J. Interaction of urea and human enamel. Caries Res 1984;18:17-24.

8. Bailey SJ, Swift Jr E. Effects of home bleaching products on composite resins. Quintessence Int 1992;23:489-494.

9. Cehreli ZC, Yazici R, García-Godoy F. Effect of home-use bleaching gels on fluoride releasing restorative materials. Oper Dent 2003;28:605-609.

10. Arcari GM, Baratieri LN, Maia HP, De Freitas SF. Influence of the duration of treatment using a $10 \%$ carbamide peroxide bleaching gel on dentin surface microhardness: an in situ study. Quintessence Int 2005;36:15-24.

11. Al-Salehi SK, Hatton PV, Miller CA, Mcleod C. Joiner A. The effect of carbamide peroxide treatment on metal ion release from dental amalgam. Dent Mater 2006;22:948-953.

12. Mor C, Steinbert D, Dogan H, Rotstein I. Bacterial adherence to bleached surfaces of composite resin in vitro. Oral Surg Oral Med Oral Pathol Oral Radiol Endod 1998;86:582586 .
13. Steiberg D, Mor C, Dogan H, Zacks B, Rotstein I. Effect of salivary biofilm on the adherence of oral bacteria to bleached and non-bleached restorative material. Dent Mater 1999;15:14-20.

14. Davis N. A nanotechnology composite. Compend Contin Educ Dent 2003;24:662-670.

15. Duke ES. Has Dentistry moved into the nanotechnology era? Compend Contin Educ Dent 2003;24:380-382.

16. Fidelus JD, Wiesel E, Gojny FH, Schulte K, Wagner HD. Thermo-mechanical properties of randomly oriented carbon/epoxy nanocomposites. Composites: Part A 2005;36:1555-1561.

17. Gojny FH, Wichmann MHG, Fiedler B, Bauhofer W, Schulte $K$. Influence of nano-modification on the mechanical and electrical properties of conventional fibre-reinforced composites. Composites: Part A 2005;36:1525-1535.

18. Mitra SB, Wu D, Holmes BN. An application of nanotechnology in advanced dental materials. J Am Dent Assoc 2003;134:1382-1390.

19. Celik C. Arhun N, Yamanel K. Clinical evaluation of resinbased composites in posterior restorations:12-month. Eur J Dent 2010;4:57-65.

20. Gurgan S, Yalcin F. The effect of 2 different bleaching regimens on the surface roughness and hardness of tooth-colored restorative materials. Quintessence Int 2007;38:E83E87.

21. De La Pena VA, Cabrita OB. Comparison of the clinical efficacy and safety of carbamide peroxide and hydrogen peroxide in at-home bleaching gels. Quintessence Int 2006;37:551-556.

22. Cavalli V, Giannini M, Carvalho RM. Effect of carbamide peroxide bleaching agents on tensile strength of human enamel. Dent Mater 2004;20:733-739.

23. Yalcin F, Gurgan S. Effect of two different bleaching regimens on the gloss of tooth colored restorative materials. Dent Mater 2005;21:464-468.

24. Wattanapayungkul P, Yap AUJ. Effects of in-office bleaching products on surface finish of tooth-colored restorations. Oper Dent 2003;28:15-19.

25. Musanje L, Ferracane JL. Effects of resin formulation and nanofiller surface treatment on the properties of experimental hybrid resin composite. Biomaterials 2004;25:40654071.

26. Prakki A, Cilli R, Mondelli RFL, Kalachandra S, Pereira JC. Influence of $\mathrm{pH}$ environment on polymer based dental materials properties. J Dent 2005;33:91-98.

27. Söderholm KJ, Zigan M, Ragan M, Fischlschweiger W, Bergman M. Hydrolytic degradation of dental composites. J Dent Res 1984;63:1248-1254. 
28. Wang L, Garcia FCP, Araujo PA, Franco EB, Mondelli RFL. Wear resistance of packable resin composites after simulated toothbrushing test. J Esthet Restor Dent 2004;6:303315.

29. Badra VV, Faraoni JJ, Ramos RP, Palma-Dibb RG. Influence of different beverages on the microhardness and surface roughness of resin composites. Oper Dent 2005;30:213-219.

30. Polydorou O, Hellwig E, Auschill TM. The effect of different bleaching agents on the surface texture of restorative materials. Oper Dent 2006;31:473-480.

31. Yazici AR, Tuncer D, Antonson S, Onen A, Kilinc E. Effects of delayed finishing/polishing on surface roughness, hardness and gloss of tooth-coloured restorative materials. Eur J Dent 2010;4:50-56.

32. Cho SD, Bulpakdi P, Matis BA, Platt JA. Effect of bleaching on fracture toughness of resin composites. Oper Dent 2009;34:703-708. 